\title{
World Health Organization perspectives on the contribution of the Global Alliance for Vaccines and Immunization on reducing child mortality
}

\author{
F Bustreo, ${ }^{1}$ J-M Okwo-Bele, ${ }^{2}$ L Kamara ${ }^{2}$
}

${ }^{1}$ Family, Women's and Children's Health, World Health Organization, Geneva, Switzerland

${ }^{2}$ Department of Immunization, Vaccines and Biologicals, World Health Organization, Geneva, Switzerland

\section{Correspondence to} Dr F Bustreo, Family, Women's and Children's Health, World Health Organization, 20

Avenue Appia, Geneva 1211, Switzerland;

bustreof@who.int

Received 8 October 2014 Revised 13 October 2014 Accepted 14 October 2014

\section{CrossMark}

\author{
To cite: Bustreo F, Okwo- \\ Bele J-M, Kamara L. Arch \\ Dis Child 2015;100
} (Suppl 1):s34-s37.

\section{ABSTRACT}

Child mortality has decreased substantially globallyfrom 12.6 million in 1990 to 6.3 million in 2013-due, in large part to of governments' and organisations' work, to prevent pneumonia, diarrhoea and malaria, the main causes of death in the postneonatal period. In 2012, the World Health Assembly adopted the Decade of Vaccines Global Vaccine Action Plan 2011-2020 as the current framework aimed at preventing millions of deaths through more equitable access to existing vaccines for people in all communities. The Global Alliance for Vaccines and Immunization (GAVI) plays a critical role in this effort by financing and facilitating delivery platforms for vaccines, with focused support for the achievements of improved vaccination coverage and acceleration of the uptake of WHO-recommended lifesaving new vaccines in 73 low-income countries. The GAVI Alliance has contributed substantially towards the progress of Millennium Development Goal 4 and to improving women's lives. By 2013, the GAVI Alliance had immunised 440 million additional children and averted six million future deaths from vaccinepreventable diseases in the world's poorest countries. The GAVI Alliance is on track to reducing child mortality to 68 per 1000 live births by 2015 in supported countries. This paper discusses the GAVI Alliance achievements related to Millennium Development Goal 4 and its broader contribution to improving women's lives and health systems, as well as challenges and obstacles it has faced. Additionally, it looks at challenges for the future and how it will continue its work related to reducing child mortality and improving women's health.

\section{BACKGROUND}

Child mortality has decreased substantially globally -from 12.6 million in 1990 to 6.3 million in 2013 - due, in large part because of governments' and organisations' work, to prevent pneumonia, diarrhoea and malaria, the main causes of death in the postneonatal period.

The magnitude of immunisation's contribution to the achievement of Millennium Development Goal (MDG) 4 by 2015 depends upon our ability to achieve and sustain universal vaccination coverage in all countries and districts, including those where child mortality rates are high and geographical, political, socio-economic or cultural barriers to effective provision and use of health services prevail. The key targets of this goal included reducing the under 5 mortality rate by two-thirds and increasing the proportion of 1-year-old children immunised against measles between 1990 and 2015. ${ }^{1}$
The achievement of MDG 4 depends on renewed efforts to prevent and control pneumonia, diarrhoea and under nutrition in all of the regions served by WHO, as well as malaria in the African region. In 2013, 6.3 million children died before reaching their fifth birthday; almost all of these deaths occurred in low-income and middle-income countries. Pneumonia, diarrhoea and malaria are the principal causes of child deaths from infectious diseases, causing about one-third of under 5 deaths; other causes include preterm birth complications, complications due to labour and delivery, lack of effective labour and delivery care, and lack of access to key interventions for newborns and mothers, among others. ${ }^{2}$

In 2000-the same year as the MDGs were established-the Global Alliance for Vaccines and Immunization (GAVI) was formed as a public-private global health partnership meant to address global inequities in access to and coverage of available lifesaving vaccines (figure 1). ${ }^{4}$ Vaccines are recognised as one of the most cost-effective public health interventions with the potential to significantly impact the unacceptable childhood deaths in the world. Furthermore, with the renewed emphasis on universal health coverage, immunisation has paved the way for-and continues to provide- an enabling platform for other child and maternal health services. ${ }^{5}$

From its founding, GAVI has leveraged the support of its strategic partners-including donor countries, recipient countries, industry, civil society, technical institutions, unaffiliated members and United Nations (UN) agencies-to impact public health. WHO was a founding partner of the Alliance, and together with the United Nations Children's Fund and the World Bank it currently supports the implementation of GAVI's mission into national immunisation programmes and in monitoring the impact of GAVI's investments in the world's poorest countries.

WHO's work with the GAVI Alliance has several dimensions. Established in 1974, the WHO's Vaccines and Immunization Programme provides global policies using the latest scientific and technical evidence. ${ }^{6}$ The past 15 years have seen changes in the vaccine community that pertain notably to new vaccines, technology development and increased funding via new financing mechanisms, including particularly through GAVI. WHO has responded through swift reforms in its policymaking structure and regularly receives advice from the Strategic Advisory Group of Experts. ${ }^{7}$

Additionally, GAVI impacts vaccine accessibility through its use of country-directed and country- 

children under 5 years, 2013.
Figure 1 Causes of deaths among

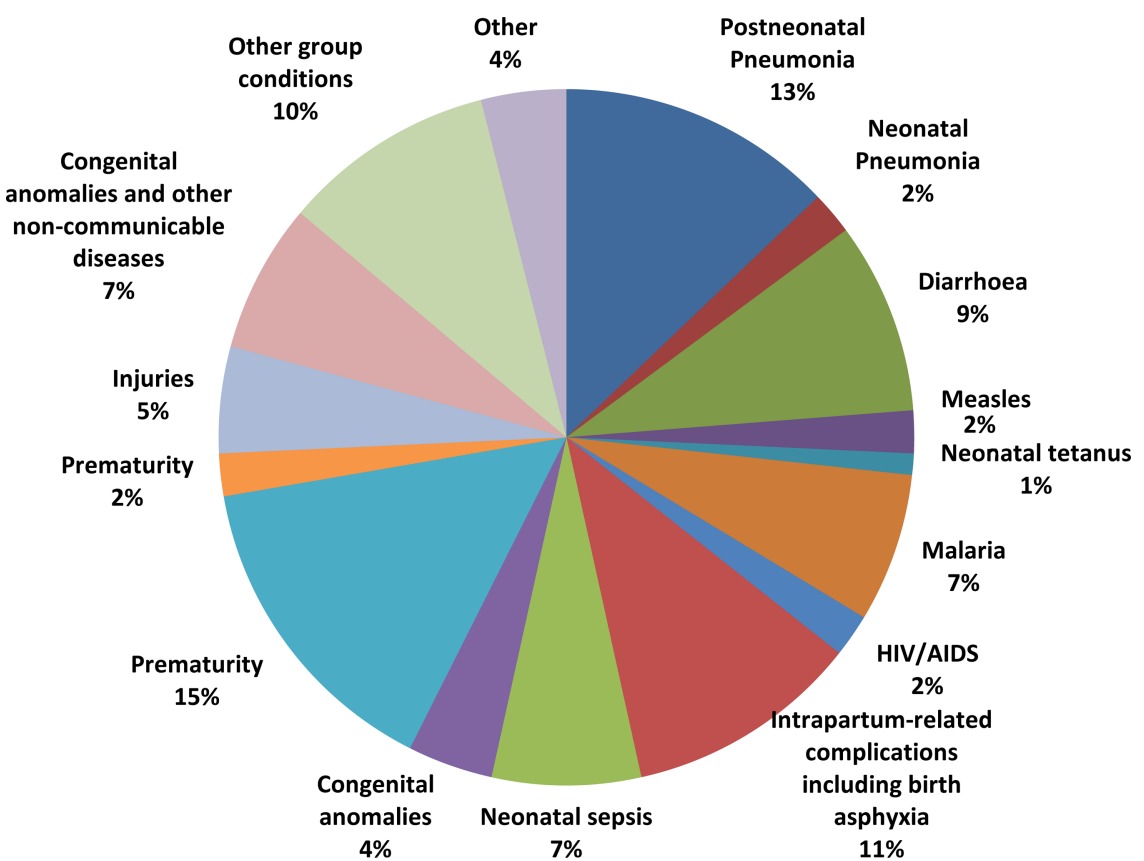

supported financing. For example, countries introducing GAVI-supported vaccines into routine schedules must co-finance these vaccines, which incentivises increased country ownership and scale-up by these countries over time towards sustained introduction by countries. By 2013, 68 countries were required to co-finance their vaccines and US\$69 million or $11 \%$ of the total value of vaccine support by the Alliance was co-financed by countries. $^{8}$

WHO also establishes international standards and norms for vaccines quality and safety and provides reference materials for use by vaccine manufacturers and national regulatory authorities for the manufacture and the control of vaccines. ${ }^{9}$ This programme operates in ways that allow manufacturers from developing countries to enter the market together with established manufacturers, leading to supplies of quality-assured products and competition that has brought prices down significantly, changing the dynamics of the market for public health-focused vaccines.

WHO monitors and assesses the trends and the impact of strategies and activities for reducing morbidity and mortality of vaccine-preventable diseases through collection, analysis and interpretation of reports and statistics on estimates of national immunisation coverage, surveillance data, immunisation schedules and indicators of immunisation system performance. ${ }^{10}$

In terms of GAVI governance, WHO is represented on the GAVI Alliance Board by Dr Flavia Bustreo and Dr Jean-Marie Okwo-Bele, where collectively with the other Alliance partners they are responsible for setting the strategic focus and policies of GAVI and in monitoring the impact of GAVI's investments and contribution to the global public health and development agenda. ${ }^{11}$ Dr Bustreo is a strong advocate for women's and children's health and her appointment on the GAVI Board coincided with the preparations for GAVI's first replenishment meeting in June 2011 and, subsequently, in November 2011 the Board's decision to invite countries to apply for funding for introduction of human papillomavirus (HPV) vaccines. ${ }^{12}$

\section{GAVI'S CONTRIBUTION TO IMPROVED VACCINE COVERAGE AND REDUCING CHILD MORTALITY}

In May 2012, the World Health Assembly endorsed the Decade of Vaccines-Global Vaccine Action Plan (GVAP) that provides the global framework for achieving equity in coverage and expanding the benefits of vaccines to all by $2020 .^{13}$ The GVAP set five targets, including the achievements of national DTP3 (three doses of diphtheria-tetanus-pertussis vaccine) immunisation coverage of $90 \%$ by 2015 with no district's coverage at $<80 \%$. The other targets are related to disease eradication and elimination to be reached at country and regional levels.

With GAVI support, low-income countries have been able to accelerate the pace of introduction of vaccines into their health systems and scale up progress towards achieving the MDGs and achieving universal health coverage. In the 73 GAVI-eligible countries, DTP3 coverage rates rose from $68 \%$ in 2000 to $83 \%$ in $2013 .^{14}$

Since 2011, GAVI has contributed to 67 vaccine introductions and campaigns. The vaccines introduced in the routine programme include pentavalent (DTP3-hepatitis B-haemophilus influenza type b (Hib) vaccines), pneumococcal and rotavirus vaccines. In addition, vaccines introduced through mass campaign strategy include meningitis and measles vaccines.

By 2013, the countries supported by GAVI had immunised 440 million additional children and averted six million future deaths from vaccine-preventable diseases. ${ }^{8}$ In these countries, the milestone set for achieving the reduction of child mortality to 68 per 1000 live births by 2015 is on track. ${ }^{15}$

\section{Pneumococcal vaccines}

Pneumococcal diseases account for 8.8 million deaths and are the leading cause of childhood mortality. ${ }^{16}$ In 2007, WHO recommended the inclusion of pneumococcal vaccines in childhood immunisation programmes worldwide, in particular, in countries with high childhood mortality. By 2015, 80\% of GAVI-eligible countries will have introduced pneumococcal vaccines; the continued scale-up of the vaccines expected by 2020 is expected to result in 1.5 million deaths averted. ${ }^{17}$

\section{Rotavirus}

Diarrhoea claims the lives of nearly half a million young children each year with more than $90 \%$ of these deaths occurring in low-resource countries eligible for support by GAVI. ${ }^{17}$ In 2007, WHO recommended vaccination against rotavirus 
infections, which can prevent severe diarrhoea in young children. GAVI has helped immunise more than four million children against rotavirus. A review of the impact of rotavirus vaccines in GAVI-eligible countries found that rotavirus vaccination would prevent 2.46 million childhood deaths and 83 million disability-adjusted life years from 2011 to 2030, with annual reductions of 180000 childhood deaths at peak vaccine uptake. $^{18}$

\section{Measles}

GAVI has also contributed to what researchers have called a 'remarkable reduction' in measles deaths for children under the age of 5 years, from 872000 in 1990 to 118000 in 2008, an $86 \%$ decline. $^{19}$ Increased measles vaccine has contributed to MDG 4 across the world. In Niger, for example, the mortality rate for children under the age of 5 years dropped significantly, from 226 deaths per 1000 live births in 1998 to 128 deaths per 1000 live births in 2009. As a result, almost 60000 lives of children under 5 years of age were saved in $2009 .{ }^{20}$ This impact is in addition to the non-specific effects (vaccines acting independently of other vaccines) of measles vaccination, which when provided with vitamin A or followed by DTP3 vaccination within a specified administration schedule can contribute to further mortality reduction from diseases other than measles. ${ }^{21}$

\section{Hib infection}

Increasing DTP vaccination coverage has led to a marked decline in Hib meningitis in countries for which impact has been measured. ${ }^{22}$ For example, in Uganda, 'infant immunization with Hib vaccine has virtually eliminated Hib meningitis in Uganda within 5 years', with vaccination preventing 28000 cases of pneumonia and 5000 deaths per year, according to a 2008 study. $^{23}$

\section{GAVI'S BROADER CONTRIBUTIONS TO MDGS}

Improving adolescent's health and women's lives

In addition to the direct contribution to MDG 4, GAVI has also contributed to MDG 5 by scaling up support for improving women's lives which includes helping girls and young women to ensure that they receive the HPV vaccine to prevent cervical cancer.

According to WHO, more than 270000 women die from cervical cancer every year. Rwanda became the first African country to launch a national school-based HPV immunisation programme in 2011 , and this year the country is transitioning from supplierdonated vaccines to a co-financing agreement with GAVI support to ensure long-term sustainability. ${ }^{24}$ By 2020, GAVI expects more than 30 million girls in over 40 of the world's poorest countries to have been immunised with the HPV vaccine. ${ }^{25}$

\section{CONTINUED CHALLENGES TOWARDS MEETING MDG 4 TARGETS BY 2015 AND BEYOND}

GAVI has faced substantial challenges related to health systems and equity as it worked to increase immunisation and vaccine coverage in supporting eligible countries accelerate progress towards related to MDG 4. Health systems have required substantial strengthening and modernising; as they stand now, these systems' condition often prevents programmes from scaling up to necessary levels. Additionally, governments in the developing countries face a number of competing health priorities with a limited budget within which they must work. By 2013, GAVI had committed just over US\$800 million in health systems support to 56 countries. $^{26}$

Supply chains are weak in many locations, creating difficulty moving temperature-sensitive vaccinations and other medications to local clinics while ensuring that these supplies are not expired. Data quality may be poor in countries that lack the infrastructure and tools to research pricing to find appropriate bids and accurately track the movement of vaccines and other medical supplies. The civil unrest and political instability observed in many eligible countries add complex and difficult-to-solve obstacles to achieving high, equitable coverage. ${ }^{27}$

The environment in which GAVI operates will look substantially different in the coming years, impacting work related to reducing child and maternal mortality. Many countries that have historically received aid are experiencing rapid economic growth and are expected to assume more responsibility for building their own social infrastructure. Fewer people now live in extreme poverty, and most of the world's poor live in middle-income countries.

In June 2014, the GAVI Alliance Board approved a strategic framework for 2016-2020 that it estimates will immunise an additional 300 million children and prevent five to six million future deaths. ${ }^{28}$ In parallel, GAVI is preparing for its second replenishment meeting in 2015 with a target of mobilising an additional US $\$ 7.5$ billion to support the implementation of its next strategy. Long-term predictable funding is critical to the continued ability of GAVI in saving lives and protecting people's health.

\section{CONCLUSION}

Since 2000, GAVI's work on vaccines and immunisations has helped prevent six million future deaths by immunising 440 million children, thus significantly advancing countries towards the achievement of the MDG 4 targets. ${ }^{29}$ In GAVI-eligible countries, the milestone set for achieving the reduction of child mortality to 68 per 1000 live births by 2015 is on track. ${ }^{29}$

Despite the great progress, GAVI has faced limitations such as weak health systems, supply-side (service availability) and demand-side (acceptability and affordability) factors, and in-country conflict. In counting down towards the MDG's deadline in 2015, countries need to accelerate both introduction of these high-impact vaccines and create the budgetary and fiscal space to sustain these vaccines in their national immunisation programmes against the backdrop of competing health priorities and limited resources. ${ }^{30} 31$

To date, GAVI, a truly innovative public-private partnership, has delivered on its promise and continues to demonstrate results, value for money and return on investment, building from the policies and standards set by WHO.

WHO notes that the full impact of vaccine-preventable diseases on child mortality reduction will not be achieved unless additional resources are made available for continued and sustained investments in the world's poorest countries. WHO is very supportive of GAVI's innovative model of ensuring predictable financing for vaccination programmes and commitment towards country ownership and sustainability. With continued support and timely introduction of vaccines in the world's poorest countries, we can significantly contribute to the achievement of MDG 4 and to the post-2015 development agenda.

\section{Competing interests None.}

Provenance and peer review Commissioned; internally peer reviewed.

\section{REFERENCES}

1 United Nations General Assembly. United Nations Millennium Declaration. 18 September 2000, A/RES/55/2.

2 United Nations Children's Fund, World Health Organization, The World Bank, United Nations, Levels \& Trends in Child Mortality Report 2013, estimates developed by UN Inter-Agency Group for Child Estimates. 
3 CHERG-WHO Data methods and data sources for child causes of deaths 20002003 (Global health estimates technical paper) WHO/HIS/HIS/GHE/2014.6.2.

4 Muraskin W. The global alliance for vaccines and immunization: is it a new model for effective public-private cooperation in international public health? Am I Public Health 2004;94:1922-5.

5 Chan M. The Contribution of Primary Health Care to the Millennium Development Goals. 16 August 2007. http://www.who.int/dg/speeches/2007/20070816_ argentina/en/ (accessed 5 Oct 2014).

6 Chan M. Beyond expectations: 40 years of EPI. Lancet 2014;383:1697-8.

7 Duclos P, Okwo-Bele JM, Salisbury D. Establishing global policy recommendations: the role of the strategic advisory group of experts on immunization. Expert Rev Vaccines 2011;10:163-73.

8 GAVI Alliance. 2013 Progress Report. Geneva: GAVI Alliance, 2014. http://www. gavialliance.org/library/publications/gavi-progress-reports/gavi-alliance-progressreport-2013 (accessed 5 Oct 2014).

9 World Health Organization. World Health Organization expert committee on biological standardization. World Health Organ Tech Rep Ser 2014:1-266. http:/ www.who.int/immunization_standards/vaccine_quality/TRS_978_61st_report_ Annex_6_PQ_vaccine_procedure.pdf?ua=1 (accessed 5 Oct 2014).

10 World Health Organization and United Nations Children's Fund. Global immunization data. http://www.who.int/immunization_monitoring/Global_ Immunization_Data_v2 (accessed 5 Oct 2014).

11 GAVI Alliance. GAVI Alliance Board. http://www.gavi.org/about/governance/gaviboard/composition/ (accessed 5 Oct 2014).

12 Bustreo F. WHO Supports GAVI Board Decision to Open a Funding Window for Human Papillomavirus and Rubella Vaccines. 17 November 2011. http://www.who.int/ immunization/newsroom/GAVI_hpv_rubella_statement_nov11/en/ (accessed 5 Oct 2014).

13 Cherian T, Okwo-Bele JM. The decade of vaccines global vaccine action plan: shaping immunization programmes in the current decade. Expert Rev Vaccines 2014;13:573-5.

14 World Health Organization and United Nations Children's Fund. Global immunization data. Geneva: WHO, 2013. http://www.who.int/immunization monitoring/Global_Immunization_Data_v2 (accessed 5 Oct 2014).

15 GAVI Alliance. Delivering Together on the 2011-2015 Strategy: Mid-Term Review Report. Geneva: GAVI Alliance, 2014. midtermreview.gavialliance.org (accessed 5 Oct 2014).

16 World Health Organization. WHO position paper on pneumococcal vaccines 2012. http://www.who.int/immunization/position_papers/PP_pneumococcal_April_2012_ summary.pdf (accessed 6 Oct 2014).

17 GAVI Alliance. Advance Market Commitment for Pneumococcal Vaccines: Annual Report 1 April 2012-31 March 2013. Geneva: GAVI Alliance, 2013. http://www.gavi.org/library/ documents/amc/2014-pneumococcal-amc-annual-report/ (accessed 6 Oct 2014).
18 Atherly $\mathrm{DE}$, Lewis $\mathrm{KDC}$, Tate J, et al. Projected health and economic impact of rotavirus vaccination in GAVI-eligible countries. Vaccine 2012;30(Suppl 1):A7-14.

19 Van Den Ent MM, Brown DW, Hoekstra EJ, et al. Measles mortality reduction contributes substantially to reduction of all cause mortality among children less than five years of age, 1990-2008. J Infect Dis 2011;204(Suppl 1):S18-23.

20 Amouzou A, Habi 0 , Bensaïd $\mathrm{K}$. Reduction in child mortality in niger: a countdown to 2015 country case study. Lancet 2012;380:1169-78.

21 Shann F. The non-specific effects of vaccines. Arch Dis Child 2010;95:662-7.

22 Lob-Levyt J. Contribution of the GAVI alliance to improving health and reducing poverty. Philos Trans R Soc Lond B Biol Sci 2011;366:2743-7.

23 Lewis RF, Kisakye A, Gessner BD, et al. Action for child survival: elimination of haemophilus influenzae type B meningitis in Uganda. Bull World Health Organ 2008:86:292-301.

24 GAVI Alliance. 1.5 million girls set to benefit from vaccine against cervical cancer. Geneva: GAVI Alliance, 2014. http://www.gavi.org/library/news/press-releases/2014/ 1-5-million-girls-set-to-benefit-from-vaccine-against-cervical-cancer (accessed 6 Oct 2014).

25 GAVI Alliance. Ghana to vaccinate girls against HPV with GAVI support. Geneva: GAVI Alliance, 2013. http://www.gavi.org/library/news/gavi-features/2013/ghana-tovaccinate-girls-against-hpv-with-gavi-support/\#sthash.Bw7a1Sis.dpuf (accessed 6 Oct 2014).

26 GAVI Alliance. 2013 Progress Report. Geneva: GAVI Alliance, 2014. http:/lwww. gavialliance.org/library/publications/gavi-progress-reports/gavi-alliance-progressreport-2013 (accessed 6 Oct 2014).

27 GAVI Alliance. Delivering Together on the 2011-2015 Strategy: Mid-Term Review Report. Geneva: GAVI Alliance, 2014. midtermreview.gavialliance.org (accessed 6 Oct 2014).

28 GAVI Alliance. GAVI alliance board approves new strategic framework to reach an additional 300 million children with vaccines. GAVI Alliance, 2014. http://www. gavialliance.org/Library/News/Press-releases/2014/GAVI-Alliance-Board-approvesnew-strategic-framework-to-reach-an-additional-300-million-children-with-vaccines (accessed 6 Oct 2014).

29 Limb M. GAVI aims to double its child vaccination rate between 2016 and 2020 BMJ 2014;348 doi: http://dx.doi.org/10.1136/bmj.g3781 (Published 09 June 2014).

30 Kamara L, Milstein JB, Patyna M, et al. Strategies for financial sustainability of immunization programs: a review of the strategies from 50 national immunization program financial sustainability plans. Vaccine 2008;26:6717-26.

31 Saxenian $\mathrm{H}$, Hecht $\mathrm{R}$, Kaddar $\mathrm{M}$, et al. Overcoming challenges to sustainable immunization financing: early experiences from GAVI graduating countries. Health Policy Plan 2014; Published online Feb 8. DOl:10.1093/heapol/czu003. 